\title{
Course Reform for Developing Computational Thinking Ability of Tip-top Talents*
}

\author{
Chunming Wu, Yuanrui Zuo, Yun Du, Xianchun Zou \\ College of Computer and Information Science, Southwest University, Chongqing, 400715, China \\ \{springsun \& zyr \& dyun \& zxc\}@swu.edu.cn
}

\begin{abstract}
Computational thinking (CT) ability is the basic quality of tip-top talents and an important index for evaluating the educational level of universities. With a deep analysis of content of CT ability, the computer course system is established, which is for developing the students' CT ability. By combining teaching practice, reform measures have been put forward in terms of orientation, teaching content and course assessment of programming course, which have obtained many teaching achievements.
\end{abstract}

Index Terms - computational thinking, tip-top talents, development of ability, teaching reform

\section{Introduction}

To improve integral level and international competitive power of university education, many universities of high level in the country have developed the reform test for development of tip-top talents [1,2]. Take our college as an example, since 2011, we have carried out "Plan of Development of Tip-top Talents of Southwest University". Through the implementation of the plan, we expect to explore new ways to cultivate innovative talents, deepen the reform of undergraduate teaching, and improve the quality of talent training. We especially founded Hanhong College, which includes Wumi Class (liberal arts), Longping Class (science). Some colleges also founded experimental area and established Innovation Class to explore the development of tip-top talents. Undoubtedly, such measures play a big part in improving the quality of talents and teaching level of the universities. However, it cannot be ignored that if we do not change traditional teaching idea and thinking, reform traditional teaching content and system, or innovate traditional teaching mode and method, development of creative talents will be beyond the scope of words.

Taken the development of information-based quality of the students as a starting point, this paper will discuss the construction of computer course in the development of tip-top talents based on improving students' computational thinking ability.

\section{Content of the Computational Thinking}

Information technology, as an important index of the 21st century, has entered various fields and exerted great influences on people's daily life, study and work and is developing and deepening with an unprecedented speed. The process of information is in the deep structure of many fields, including biology, physics, economics, management, art and politics, etc.
Information-based quality has been a basic quality of contemporary university students, which makes computer teaching essential in higher education. However, there is much difference between present and traditional computer teaching. Traditional computer teaching focused on explanation of detailed knowledge, such as the file management, word processing, setting the operating system and so on. While today, new concept and technology are increasingly emerging, such as cloud computing, Internet of Things, microblog, QQ and Wiki, etc. How can students obtain such knowledge? To know so many new technologies or to learn the skill of quickly grasping the new technology? If we choose the latter, what on earth will we teach in the class and how? These questions are not strange to us, however, when we are faced with development of tip-top talents, they become so urgent.

In 2006, Professor Jeannette M. Wing from American Carnegie Mellon University put forward for the first time the concept and idea of Computational Thinking (CT) [3]. She holds that CT is taking an approach to solving problems, designing systems, and understanding human behavior that draws on concepts fundamental to computer science. It contains a series of conceptual activity of computer science and stresses that like reading, writing, and arithmetic, CT will be a fundamental skill used by everyone in the world, not only belonging to the computer scientist. Computing has become the third scientific research method besides theory and experiment $[4,5]$. This concept has been paid much attention and provoked discussion by many scholars from computer field, sociology field and philosophy field both at home and abroad since its emersion.

In 2010, The C9 Alliance in the country began to explore this teaching concept to guide relevant teaching reform and practice and they obtained funds from the Ministry of Education, Ministry of Science and Technology and many other ministries. In the recommended guideline of feasible projects in information technology field of national science and technology plan 2012, it set up the project for the first time and developed research of "software methodology of a new version and its supporting mechanism for CT", which drove $\mathrm{CT}$ to an unprecedented height.

The reason why teaching content of CT is given so much attention is that it adopts many kinds of methods to solve problems, such as general mathematics thinking method, general engineering thinking method for designing and

\footnotetext{
* This work is partially supported by Teaching Innovation Project of Southwest University\#2012JY204 and \#2011JY028 to Chunming Wu.
} 
evaluating huge and complex system, general scientific thinking method for understanding complexity, intelligence, psychology and human behavior, and it is more general with a wider divergence surface, which is the basic quality that contemporary tip-top talents should grasp [6,7]. Besides, it is also an important index to assess tip-top talents.

If previous computer education of the universities was to teach students how to use computers, the present computer education is trying to teach the students how to understand the computer system and in the future the universities will teach the students how to grasp CT and really achieve the goal of "Teach a man how to fish", as shown in Fig. 1.

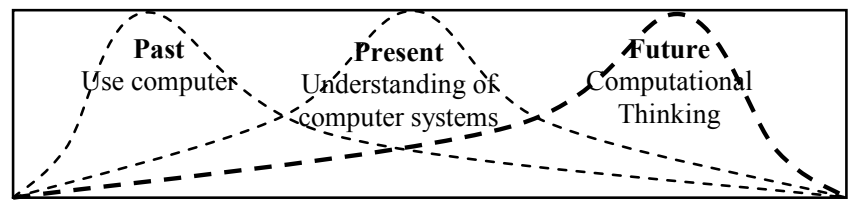

Fig. 1 Responsibility evaluation of the universities in computer teaching

\section{Construction of Computer Courses System Based on the Development of CT Ability}

In the stage of primary and secondary school education, our country always practices exam-oriented education mechanism based on marks, which makes most of the students form a thinking set and behavior mode passively obtaining knowledge. Considering this situation, the development of tiptop talents cannot seek quick results, which first of all requires hierarchy of development of CT reflected in the course system. Take our university as an example, we put forward the measure of "three-stage ability development for CT" according to the development goal of college and combination of reality of the students themselves, shown as Fig.2.

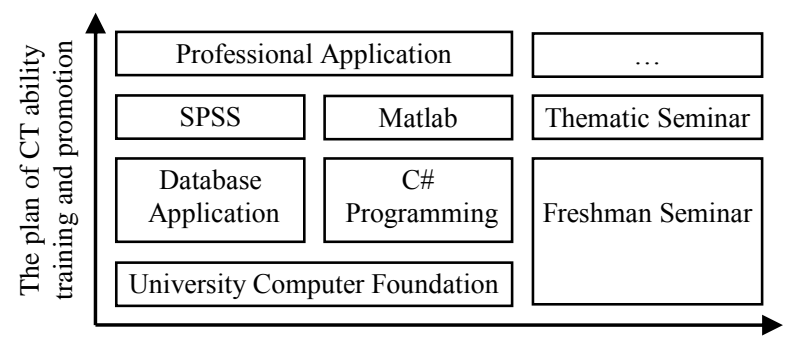

Fig. 2 Development of CT ability and three-stage teaching

In the first stage, develop basic information-based quality of the students through the "University Computer Foundation" and make them skillfully operate the computer and solve the common problem in daily life. In the second stage, comprehensively improve CT and logical thinking ability through Programming Course (Wumi Class is "database application" while Longping Class is "C\# programming" ) and make them fully understand the computer system, think and solve problems like computer experts, expand such ability to study and apply other subjects and lay foundation of students' ability to solve real problems. In the third stage, develop students' creativity ability through practical technology courses (Wumi Class is "SPSS" while Longping Class is "Matlab") and make them grasp the basic technology, solve scientific problems in later study and work with method of CT. Besides the above three-stage course teaching, we also irregularly set freshman seminar and special thematic seminar to let the students know the latest technological achievements and technological innovation both at home and abroad. Make them always hold scientific progress, having wider international view.

Corresponding to the course system, we established the associated course teams for each course and develop systematic research on teaching content, teaching method and teaching case based on characteristics and requirements of the development of tip-top talents.

\section{Course Teaching Practice for the Development of CT Ability}

CT is not only a teaching concept, but also a teaching method. In our course system, programming courses play a transitional role, which is a check for habit and study method of the students in early study and also a basis of development of students' creative ability. The course itself blends mathematical thought, modularitied designing thinking, contrast and optimization strategy and many other research methods. With study of programming, logical thinking and abstract thinking of the students can be well developed and CT ability is also improved, which should be given special attention and mainly constructed [8].

To let the students really grasp CT, we must reflect the gradualness and scientificity of the development of CT in teaching method. We think that we should first of all deeply analyze demand target, intelligence level, cognitive basis and cognitive characteristic of the tip-top talents and only by doing so, can we specifically develop teaching activity; secondly, we should consider various problems may exist in the teaching arrangement, for example, there is big difference in students' computer base and their study interest. How to organize teaching contents and make teaching plan according to students' different bases? Many methods of CT are formed in the process of scientifically establishing computer system. How to provide the students with the scene of "How does the computer expert think"? Each subject should be based on theory with knowledge of methodology level. During establishment of programming courses, how to effectively combine basic theory and practice?

Take "Database Application" set by Wumi Class as an example, the target of our course is to make the students learn to produce a small management information system based on WEB, make the students learn what is related to the database, SQL, HTML, WEB service and network programming (such as ASP), let the students have a full understanding of the Internet that they contact every day and fully know the working mechanism of WEB system. Our final target is to make the students grasp CT ability, develop a habit of independent study, learn the general method to solve problems 
in daily life. We take the following teaching reform according to the above targets:

\section{A. Implement "Less Theory, More Practice"}

In teaching concepts, we concentrate on "less theory, more practice" in accordance with characteristics of arts students, aiming to make students think, absorb and gain knowledge during experiential learning process, acquire ideas, ways and methods during research-style learning, learn to analyze and solve problems by information technology, enhance the understanding and acquaintance of subject ideas essence, and finally use this idea and skill as a powerful tool to learn lessons, develop personalities and innovative ability.

\section{B. Classify Teaching Content in Details}

Due to many knowledge points and limited course period, we classify teaching content in details and choose knowledge in direct relationship with course objectives, and clear the task and the purpose of every class. The teaching modules of the "Database Application" was shown in Fig.3.

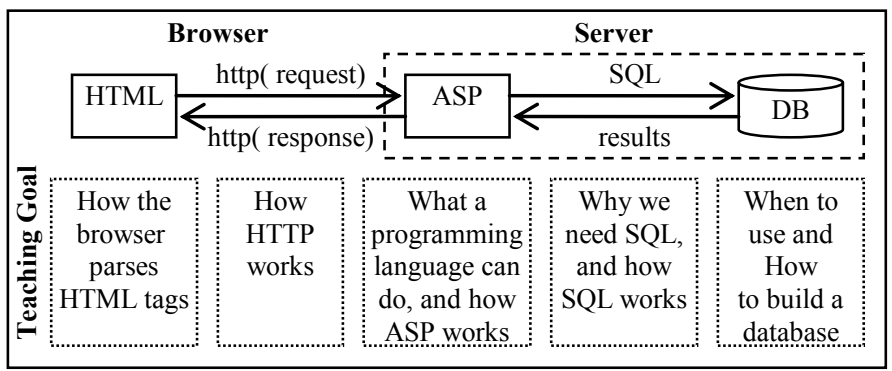

Fig. 3 The teaching modules of the "Database Application"

\section{Use "Case Study"}

Use "case study" method and prepare some practical and interesting teaching cases elaborately for each lesson. Take guidance as the principle thing, highlight analysis of basic ideas and method, clarify important and difficult points and preserve some time for self-study. For example, we will set an application scene, for database design module, and let students build database by themselves, analyze the problems (such as exception on INSERT, DELETE, UPDATE, or lack of Referential Integrity), integrate the method of database design, and turn nonobjective boring database theory to hypostatic troubleshooting tools.

\section{Establish Perfect Digital Resource Base}

Establish a perfect digital resource base of "independent study" marching with the teaching module, which first can directly provide information of independent study and secondly train students' ability to make use of the network to look up literatures with designated network resource which they must look for by themselves.

\section{E. Apply Independent Study Mode of "Task-Driven"}

Assign after-class tasks corresponding to module teaching, which can firstly urge the students to practice and make them better understand the knowledge acquired in class and secondly can develop students' habit and method of solving problems by themselves.

\section{F. Display and Mutually Evaluate the Students' Works}

We organize students to carry out peer evaluatation their works, learn others ideas and note the strengths and weaknesses of their own works. At the same time, we show in class the excellent works and give them positive feedback, which can encourage the students to study to a large degree and is also an inspiration to other students.

\section{G. Establish Scientific Assessment Mechanism}

In order to measure the teaching effect objectively and motivate students to learn independently, a scientific assessment mechanism should be established. Compared with the "case study" and "Task-Driven", we calculate mark of each every module into the final mark, to strengthen assessment for study process.

It has been proved by practice that the above teaching methods have obtained good effect. The students claim that after a semester of study they have a full understanding of the whole network structure and have solution to the network problem that they may have later. Some students even fall in love with computer science and want to be engaged in professional study.

\section{Summary}

CT is the basic quality that modern tip-top talents should possess. It is also an important index to measure educational level of colleges and universities. As information technology springs up, to solve problems through the idea and method of information technology has become more and more concerned items for innovative talent cultivation. During cultivation of tip-top talents, the reform of computer course to meet the demand of the era and to develop CT ability of students requires efforts and exploration of numerous computer teachers.

\section{Acknowledgment}

The author would like to thank Yungang Li, Huan Bai, Jian Qin, Junmei He, Boqin Liu from Computer Foundation Department of Southwest University for their teaching practice and digital information resources construction.

\section{References}

[1] Xianfeng Zeng, Xiaofang Liao, "Computational Thinking training of liberal arts students based on programming class", Computer Education, no. 4, pp. 84-87, April 2012.

[2] Qin Mou, Liang Tan, "Research and Progress in Computational Thinking", Computer Science, vol.38, no.3, pp.11-15, March 2011.

[3] Wing J M, "Computational Thinking". Communication of the ACM. vol. 49, no.3, pp. 33-35, 2006.

[4] Bundy A, "Computational Thinking is Pervasive". Journal of Scientific and Practical Computing. Noted Reviews, vol.1, no.2, pp.67-69, 2007.

[5] Wing J M, "Five Deep Questions in Computing". CACM, no, 51, pp. 158-160, 2008.

[6] Information on http://wiki.acm.org/cs2001/index.php?title=Main_Page.

[7] Philips P, "Computational Thinking: A problem-solving tool for every classroom". Information on http://www.csta.acre.org/

[8] Huamin Ren, Ming Chen, "Research on Cultivating Applied Talents with Computational Thinking", Computer Education, no.5, pp.61-63, March 2010. 